\title{
An Inquiry into a Normative Concept of Legal Efficacy
}

\section{ANDRE SANTOS CAMPOS}

Abstract. This essay argues that legal efficacy understood as existent binding force and as dominance of a system of coercion vis-a-vis competing systems is not strictly a matter of fact, but involves what can be termed justified normativity in a factual context. The argument is divided into four sections. The first three sections describe different dimensions of a normative concept of legal efficacy applied to legal systems: efficacy as persuasiveness, as indirect communication, and as constitutive obedience. The final section focuses on the efficacy of individual norms and adds a new criterion - membership - which establishes a multi-layered test of efficacy.

\section{Introductory Remarks}

Among the basic elements that comprise the tests for the identity of legal systems and norms, efficacy is in all likelihood the least controversial. Natural lawyers and legal positivists share the view that there is no law in force unless there is a coercive order that is generally adhered to by at least certain sectors of the population. For the most part, all legal theories seem to agree that legal systems must by and large be socially efficacious as a necessary condition for the existence of actual positive law rather than defunct or prospective law. They differ only on matters such as whether "law in force" means a legal system or an individual norm in a legal system, whether internalisation is a significant aspect of normative force, or whether efficacy refers to the entire population or only to specific groups submitted to the legal system.

In the light of this apparently undisputed consensus, one could assume that determining whether a legal system is by and large socially efficacious is a simple task. Efficacy would appear to be the actual binding force of norms in a group, that is, the factual existence of law. It would not be a normative concept per se insofar as a norm, in order to be efficacious, would not necessarily have to be subject to judgements prescribing that what is stipulated by the norm referred to in the judgements ought to be done. The determination of efficacy would be a simple matter of fact. However, some problems seem to arise from this consideration.

The characterisation of a system as "by and large efficacious" presupposes that unanimity of acceptance and/or conformity with the legal system is not absolutely necessary and that there is no undisputed method of computation or a certain quantitative threshold that can be universalised. Except for cases of complete 
inefficacy, the levels of efficacy that allow for the identification of law in force cannot be determined exactly. Nevertheless, even though efficacy can be determined statistically in various degrees, it can only function as a criterion of binding law absolutely. For the purposes of determining the existence of bindingness, legal systems can only be efficacious or inefficacious: They cannot be so more or less.

This vagueness gives rise to a theoretical challenge to the law's prevailing abhorrence of arbitrariness. In cases of political unrest that are evident mostly in times preceding revolutions or civil wars, determining whether a system is "by and large" accepted can be problematic, especially when silent majorities make their silence difficult to interpret or when the sectors of the population in charge of managing the legal system openly disobey certain norms. The problem is not that of establishing a sociological method of ascertaining efficacy, but rather that of finding a theoretical yardstick that determines a minimum threshold of acceptance of a law's bindingness in the light of which disagreement with the law's content is necessarily an exception. The problem of efficacy does not involve quantitative tests developed by sociologists concerning how far laws are actually obeyed (whether through descriptive or inferential statistics about levels of compliance with established laws), but rather a yes-or-no condition for the existence of law in force. $^{1}$

As a result, efficacy is not just a matter of ensuring that the law referred to is the actual law of a society rather than a past, future, or imagined system. It is also a matter of establishing what it means, theoretically and practically, to say that a legal system is in force in a given community. Societies can be exposed to competing systems of coercion that base a claim to authority either on a presupposed norm or on a practised norm. The qualitative yardstick that attributes by-and-large efficacy to one system of coercion to the detriment of any other competing system must then be the characteristic that describes how the overlapping system has dominance over the others (Alexy 2010, 90; Hoerster 1987, 184). The identification of dominance turns efficacy into a criterion that qualifies claims to authority as actual exercises of authority.

For this reason, the conceptualisation of efficacy proposed in the following should be used carefully when compared with other concepts, in particular legal existence and validity. Insofar as it identifies actual dominant exercises of authority, efficacy depends upon claims to authority existing in a factual context. However, efficacy as synonymous with factual existence (Bulygin 1990) is different from what is often referred to in jurisprudence as normative existence (Nino 1978). In the first instance, to state that a legal system or norm exists as efficacious is to state a fact: A theory of legal efficacy concerns the criteria in the light of which elements

\footnotetext{
${ }^{1}$ The concept of normativity employed in this context does not have to be especially rich but it must emphasize the ascertainment of efficacy as something more than a mere identification of the factual existence of law in descriptive terms. The use of a normative concept of legal efficacy (or what might be termed "normative efficacy") refers here to the determination of the threshold dividing actual binding law from nonlaw or from nonbinding law, which could prove useful in difficult cases such as those involving conflicts of norms and of sources that already seem to comply with the minimum formal (or even moral) requirements of lawfulness.
} 
with the general appearance of legal systems or norms can be qualified as existing binding law. In the second instance, to state that a legal system or norm exists normatively is to lay down an obligation to obey the system or norm in question. This is an entirely different notion of existence, independent of fact, that can only be relevant to the identification of efficacy if it also exists in fact.

In addition, efficacy is often treated as synonymous with legal validity, but here again a distinction is called for. It is true that there is hardly a functional concept of legal validity that does not include efficacy as one of its determinant conditions. Nevertheless, there are two approaches to the relation between efficacy and validity. According to the essentialist approach, the term validity indicates the actual existence of a system or norm, contrary to the case of a past, future or imagined system or norm; efficacy is here a necessary (and perhaps even sufficient) condition of validity (Ross 1998). On the other hand, the pragmatic approach relates validity to the problem of determining which legal norm may be applicable in a given case. In this sense, validity refers to that quality which attaches or is attributed to an individual norm and which determines more or less conclusively whether it is to be treated as belonging to a given legal system; here, efficacy is a necessary, albeit insufficient, condition of validity. However, a normative concept of legal efficacy does not necessarily have to adopt one of these approaches to the detriment of the other. Insofar as it identifies dominant systems and norms of law, the question regarding the status of its participation in legal validity must be dealt with within the context of theories of legal validity.

But how can dominance be identified? How can an official adhere to and be bound to this system of coercion rather than that based on his/her perception of the fact that this is dominant vis-a-vis the other? The aim of this essay is to show that efficacy as dominance is not strictly a matter of fact, but mostly of what can be termed justified normativity in a factual context. The following argument is divided into four sections. The first three sections present different perspectives of a normative concept of legal efficacy (each perspective developing the idea of efficacy as "justified normativity in a factual context" in accordance with a different conceptual scheme) applied exclusively to legal systems. Efficacy as persuasiveness reflects the Razian sense of reasons for action that succeed in creating actual bindingness, whereas efficacy as indirect communication resorts to Kierkegaardian terminology in order to explain how persuasiveness occurs from the standpoint of an addressee of the legal system. On the other hand, efficacy as constitutive obedience utilizes the analytical distinction between constitutive and regulative norms for the purpose of establishing that justified normativity in a factual context depends more on obedience rather than issuance as requirements of existing legal systems. The final section will show that this concept of efficacy, applied to individual norms, has an additional dimension that is also a sufficient condition of efficacy: that of membership of an efficacious legal system. In the end, it will be possible to establish that efficacy is an important issue for legal theory that cannot be left in the hands of sociologists alone.

\section{Efficacy as Persuasiveness}

Factual dominance relates to legal systems that are actually in force. The notion of "being in force" can have a variety of explanations, especially in the context of legal 
positivism. ${ }^{2}$ For instance, Kelsen $(1949,39)$ claimed that law is in force if it is generally obeyed by legal subjects or applied by legal authorities; Ross (1968, 93; 1998, 158) required law to correspond to certain social facts in which a pattern of behaviour was followed in a society and felt as binding; Hart $(1994,110)$ equated "being in force" with conformity with the rule of recognition, that is, the rule whose existence and content is determined by the fact that members of an institutional framework such as the judicial bodies of a legal system take the internal point of view towards a certain behavioural regularity and use it to evaluate the bindingness of norms that fall within their purview. These are different ways of understanding efficacy as a strict matter of fact.

However, the establishment of a principle of efficacy that determines exclusively whether a normative system is a legal system in force is not bereft of difficulties. Raz, for instance, identified some such obstacles, especially when referring to the empirical observation of obedience to rules. The first consists in the arbitrariness of the methods of computation regarding acts of compliance and transgression; the second questions the idea that offences should have equal weight when measuring efficacy; the third focuses on whether irrelevant circumstances should be taken into account; the fourth underlines the importance of knowledge of the law; the fifth emphasises the need to measure the use of powers and not merely obedience to duties; and the sixth advances the hypothesis that important constitutional laws should be more important than other laws when measuring efficacy (Raz 1970, 205). Indeed, what does it mean to say that a legal system is efficacious? Does it mean that efficacy is a necessary condition of the existence of all the individual norms in the system? Or rather of the majority of norms? Or perhaps of only those norms establishing the fundamental blocks of the system, such as constitutional norms? Do primary norms need to be efficacious at the same level as secondary norms? Or can a legal system be called efficacious merely because it is an order or coercion facing no competition from other systems of coercion at a given time and place? Can the mere absence of insurrections, civil wars, revolutions, or generalised illicit disobedience justify the claim that there is an efficacious legal system?

The ascertainment of facts seems to presuppose criteria determining which and how facts can be ascertained. The mere sociological observation that certain norms are generally obeyed by legal subjects or applied by legal authorities fails to become an adequate method of determining efficacy for two reasons. First, there is no quantitative threshold of compliance, and application besides unanimity is unquestionable. Second, there is no undisputed qualitative criterion determining the object to which quantitative tests of efficacy can be applied (for instance, which norms, or which addressees). In addition, efficacy cannot be established exclusively from an external point of view insofar as such a standpoint presupposes a

\footnotetext{
${ }^{2}$ Natural lawyers who rely on the minimum social efficacy of legal systems are not concerned with what makes a system efficacious or nonefficacious. The reason is that legal bindingness emerges for them chiefly from the moral status of efficacious norms, regardless of what makes them efficacious or not. Since they can only evaluate the moral status of legal systems and norms once they have identified the object of their inquiry (actual legal systems and norms in force), they require efficacy as a methodological first step in their axiological tests. That seems to be the full extent of the prominence attributed to efficacy in natural law theories. It is altogether different with positivist theories since they rely heavily on efficacy to identify the existence of valid legal systems and norms.
} 
distinction between actual binding force and efficacy, that is, between norms actually binding their addressees to certain obligations and the verification of subsequent facts coincidental with the contents of such norms. This distinction, however, is far from clear since it implies that the facts of rule-following or ruleapplication derive from judgements of imputation (Kelsen 1967, 76-84), which is always logically subsequent (a posteriori) to the contents predicted in the rules. This relation of facts to norms fails to explain how norms can provide genuine reasons for action rather than mere explanatory reasons of actions, that is, how norms actually exist in force (and not just due to formal membership to a normative chain of validity) before subsequent facts related to their contents can be ascertained.

This argument gives rise to the need for a method of determining efficacy that takes into account the internal point of view of addressees. However, the emphasis on motivations for considering a norm binding is also subject to certain difficulties. For instance, Ross's claim that there are no norms as such before actual application and obedience entails that the definition of norms includes empirical criteria: Norms exist only if there is a minimum level of general observance to norms. This creates a circular argument. The discovery that a certain pattern of behaviour is generally followed in a society depends upon the prior identification of such a pattern of behaviour. Supposedly, the pattern of behaviour whose observance will be measured constitutes the content of the norm that is already "felt as binding"; but since a norm is only binding after the pattern of behaviour is followed, there is a circularity that fails to provide the source of actual legal bindingness. If norms are only binding (in force) when they are complied with, and compliance is only observable after the norms are identified and "felt as binding," how can they be "felt as binding" when they are established for the very first time? This notion of efficacy fails to explain how legal systems and norms come about, that is, how they come into force in the first place.

Another example is to be found in Hart's notion of efficacy from the internal point of view: "the view of those who do not merely record and predict behaviour conforming to rules, but use the rules as standards for the appraisal of their own and others' behaviour" (Hart 1994, 98). Hart does not produce an essay in descriptive sociology since his emphasis on the internal point of view to measure the efficacy of a given social practice prevents him from being the typical sociologically inclined jurist. ${ }^{3}$ Nevertheless, this presents new challenges to Hart's rule of recognition. His distinction between an external point of view and an internal point of view does not seem to offer an explanation of the source of efficacy, namely, how an official is capable of determining the internal point of view of other officials.

Hart states clearly that the reasons judges and other officials have for following certain norms about the identification of the sources of law in their legal systems are closely tied to the fact that other officials follow those same norms. But how does an official determine the fact that other officials follow those norms? Certainly not by simply observing their conduct of compliance with specific norms, since

\footnotetext{
${ }^{3}$ Hart never uses the methods usually associated with sociology of law, such as the use of fieldwork, statistics, or case studies. Within such a frame of reference, the external point of view which is the typical object of study of sociology fails to provide a constitutive rule of any sort (Lyons 1984, 57). For an example that takes seriously Hart's remark that The Concept of Law is also a work of "descriptive sociology," see Ross 2001.
} 
that would imply a typical external point of view in the determination of efficacy. On the contrary, norms about the identification of the sources of law are efficacious if officials accept them from the internal point of view, and it is this acceptance in addition to their general behaviour of compliance that makes up the fact that they are following those norms. Efficacy becomes normative (that is, it creates an actual duty that officials are bound to follow) only when the agents involved in the social practice of identifying the sources of law of a given system also become by and large the addressees of the compulsory character of those practices. In addition, officials only become addressees when they are able to identify the fact that other officials are not merely agents but also addressees. In other words, normative efficacy depends upon an "external-internal" point of view according to which the official evaluates externally the internal point of view of other officials. ${ }^{4}$ This involves more than simple conceptual analysis and more than the mere intuitive perception by the official that others indeed follow the norms whose contents can be observed in their practices.

The determination of dominance or binding force in a legal system cannot rely on the intuitive perception of what is accepted as binding in a community or in a specific section of the community, since that would bring uncertainty to the legal system in the sense that it would rely exclusively on the official's personal (internal) opinion. Rather, the official determines efficacy by having an awareness of how a specific system of coercion with a claim to authority is sufficiently persuasive to him/her as a member of the community. The official identifies what is by and large accepted by evaluating reasons for compliance (the internal point of view) addressed to a specific community (the external point of view), in what constitutes something akin to an external-internal point of view. The official must not ask whether the contents of a system of coercion make sense as binding on him/her, but whether they are likely to make sense to everybody under the sway of such a system, including him/her.

The upshot of this argument is that efficacy characterises existing law (in force) only from such an external-internal point of view. Efficacy is here a matter of fact that cannot be blind to normative justification. In this sense, binding force implies not only that one ought to do what the norm prescribes, but also that the norm is actually justified vis-a-vis its addressees. If a norm stipulates that some act is obligatory, to predicate of such a norm that it is binding implies the statement that there is an obligation to perform that act. This is not the same as merely saying that there is a norm prescribing such an obligation and that people generally adhere to its contents; rather, it entails the statement that the norm succeeds in creating the obligation it prescribes. This success is a normative rather than a strictly factual element, but it can be an expression of efficacy: It means neither that the norm is

\footnotetext{
${ }^{4}$ Strictly speaking, internal statements concerning legal bindingness are not statements that a relevant rule is in fact accepted by the speaker or anyone else; rather, they are statements of what the officials think is right, not of what they think everyone else thinks is right. Hence, in the semantics of Hart's internal point of view, it is not necessary that the content of what each official would give as her internal statement concerning legal bindingness coincides exactly with the content of what a sociologist would describe as the bindingness that the system "has." However, even though the internal and external statements differ semantically, no system of law can be called "efficacious" based on the internal point of view alone; thus the need to develop an intricate "external-internal" point of view in order to assert the bindingness of a legal system.
} 
rationally justifiable in general terms nor that it provides rational grounds for overruling any competing systems of coercion, but rather that its claims to authority are persuasive in creating authority towards those subject to it.

Efficacy as persuasiveness entails considering the amount and the strength of reasons for judging a system of coercion as binding in a specific community of addressees. Such reasons are inherent in the system's norms and they must be reasons for action and not merely reasons for belief (Raz 1985, 296). In order to be efficacious, a system needs thus to provide sufficient reasons for action that can be accepted as such by its addressees in such a way as to avoid a blatant contradiction between the contents of the norms and the structure of beliefs and values associated with the addressees. This means that reasons for action are all those motives in the light of which someone becomes bound to act in a certain way, regardless of their contents; even the thought that " $\mathrm{A}$ is the best action for me to perform, the most reasonable injunction directed at me" will not necessarily move me to perform A unless I care about doing what is best or want to do what is reasonable; the efficacious reason for action is the one that will make me care about the performance of such or such an action. In addition, the efficacious system needs to provide sufficient exclusionary reasons (Raz 1979, 16-9) in the light of which competing systems of coercion fail to provide sufficient reasons for action to the same addressees, albeit they may still provide sufficient reasons for belief.

Hence, an efficacious legal system cannot be composed of laws that do not express a judgement on what their addressees ought to do. It is impossible that the best justification of norms may never have been thought of, let alone not endorsed by anyone. There is no need to find a Hercules to work out what the law is, because all legal officials are in a position to determine whether laws are persuasive to them as members of the community of addressees (whoever these may be; I shall address this problem in the following section). Unlike what is often implied with regard to the notion of efficacy (Bulygin 1990, 45; Dworkin 1978, 293), there is no necessary gap between a normative notion of binding force and the positivistic insistence on facts.

The element of normative justification in efficacy is an evaluation of the authority of law. It requires the contents of the norms comprised in the legal system to provide reasons for action and dominance that are consistent with the expectations held by its addressees concerning what constitutes a legitimate authority. The more a specific system of coercion has compatible reasons for being considered binding (that is, the more a system is capable of justifying its claim to authority in compatible sources and criteria of validity), the more it is efficacious in this sense. A system whose inherent set of reasons for compliance includes reasons (such as legal sources and criteria of validity) that are liable to being persuasive to all the sections of the population and to each and every member of the community is necessarily by and large efficacious. A system whose inherent set of reasons for compliance either includes reasons that are liable to persuade only certain sections of the community or excludes reasons that would be liable to persuade members of the community that remain otherwise unpersuaded is not by and large efficacious.

Persuasiveness is thus justified normativity in a factual context. This can be termed a characteristic of legal efficacy. It is a matter of fact insofar as it must take into account the expectations, values, and beliefs shared in a specific historical community; and it is a matter of justified normativity insofar as it must take into 
account inherent reasons for action. Efficacy is the point of intersection between the reasons inherent in legal systems and the ideals that addressees are likely to consider reasons for action. This is also the point of intersection between the external and the internal points of view.

\section{Efficacy as Indirect Communication}

Efficacy can only be imputed to a group formed by the norms' addressees. The identification of the addressees that comprise the group over which the efficacy of a legal system will be tested is far from being unanimous. Sometimes efficacy refers to the entire population; at other times, it refers only to specific sections of the population, such as officials.

This problem is similar to what is known in the literature on democratic theory as "the problem of scope" or "the boundary problem," which concerns the legitimate demarcation of the units within which democracy will be practised. In this case, the boundary problem can be formulated as follows: How is it possible to decide who legitimately makes up the group of individuals who are bound together for the purpose of measuring efficacious systems or norms?

The main difficulty is that every attempt to solve the boundary problem of efficacy by appealing to the norms whose efficacy is to be measured is bound to lapse into an infinite regression. The addressees of primary norms are those over whom the legal system has jurisdiction in the sense that secondary norms license the use of authority over them. A U.K. citizen living in Wales is not expected to be the addressee of a criminal law in force in Bangladesh unless it comes into contact with the criteria established by Bangladesh's secondary norms licensing the use of authority over him/her. The fundamental problem that arises here is that the addressees of secondary norms who are to constitute the group in which efficacy is to be measured are only identified as those who are bound to such norms insofar as the norms identifying them are already in force, that is, are already efficacious. For instance, in order to check whether Hart's rule of recognition is efficacious among officials (whether it exists or not), the norm identifying the characteristics of those who are to be considered officials must already be efficacious; but this norm, in turn, can only be efficacious if the procedures by which it becomes binding are already accepted as binding and followed by a generalised group of addressees; and these norms, in turn, can only be efficacious if the norms by which the characteristics determining who can be included in this generalised group of addressees are also efficacious, and so on.

One of the most celebrated ways of overcoming the problem is, for instance, the "all affected interests" principle, according to which the justification of authority is owed to all persons whose interests are affected by its exercise (Goodin 2007; Shapiro 1999). This is problematic in the case of secondary norms since they have very specific addressees even though their application is bound to affect the interests of people not included in the group. Another attempt at overcoming the problem is the principle of coercion, according to which those subject to any kind of institutional coercive power help to determine (by their acceptance and/or compliance) whether and how that power is exercised (Abizadeh 2008; Lopez-Guerra 2005). However, this is also problematic since the claim that law is necessarily efficacious 
when it is coercive seems to identify law with the preconditions for its existence (Lamond 2001).

In order to prevent infinite regression, the boundary problem can be precluded by appealing to standards that identify the addressees of a legal system and that are somehow immune to efficacy. Efficacy in this sense presupposes a preefficacious moment suggested by an established practice, resembling the moment of pre-understanding in the hermeneutic circle.

The conditions determining the scope of efficacy are similar to the conditions of persuasiveness. A claim to authority is persuasive only when it is directed at someone who is liable to accept the reasons for compliance. It entails a form of communication. However, the term communication can be used in two different ways. On the one hand, it can be used to describe someone who attempts to pass something on to someone else; if my wife tells me not to forget to take out the trash, she has communicated something, regardless of whether I have heard her or taken notice of what she has said. On the other hand, the term is often used to indicate successful communication. In this context, someone communicates only if the message has in some way been properly received by the one communicated to. If I fail to acknowledge what my wife tells me, she has not communicated, though of course the blame for the failure may be entirely mine. This sense is important to legal efficacy and might help overcome the problem of scope.

The scope of efficacy is determined by the fact that norms become an actual form of communication; and communication is a basic feature of persuasiveness. However, in order for nonefficacious standards to become binding, they must be understood and adhered to as binding. Within such a frame of reference, communication only takes place when someone receives a message. Until it is received, the "message" is not a form of communication but only an attempt at communication. A nonefficacious standard can be compared to someone speaking to himself in a desert; it is only constitutive of communication when it is actually heard and understood by someone else. This "someone" who receives and understands the message by involving himself/herself in the meaning implied therein can be called its addressee. This requires not merely communication but what Kierkegaard called "indirect communication" (Kierkegaard 2009, 73-80).

Kierkegaard's notion of indirect communication can be an invaluable tool for the identification of legal efficacy. He distinguished between objective and subjective communication by linking them to objective and subjective understanding. Objective understanding can be directly or immediately passed on to another person; it is an understanding of results, where communication is appropriately direct. In contrast, subjective understanding is not communication of results but of means; it cannot be directly or immediately passed on to another person, but requires an indirect form of communication. If a historian discovers some fact, this new knowledge can be transferred to someone else with little effort on the part of the beneficiary; direct communication requires a kind of reflective understanding on the part of the recipient, but it can be an abstract understanding of the relevant concepts. Subjective understanding, in contrast, bears on a person's own experience, for instance, the effort involved in the historian's discovery. In this case, for genuine communication to occur and genuine understanding to be achieved, the recipient of the communication must be able to do more than grasp what the communicator says abstractly. The recipient must in some way think through the meaning of 
what is said concretely in relation to his/her own life. Here the effort that the communicator has exerted to gain this understanding cannot be directly or immediately passed on as a result, but something like the means that the communicator has followed to gain the understanding must be reduplicated by the recipient (Evans 2009, 30).

Kierkegaard $(2009,73)$ described this as the requirement of "double reflection." Genuine subjective understanding requires a person first to grasp the relevant concepts (first reflection), but then to go on and think through what it would mean to apply those concepts to the person's own life (second reflection). Without such a subjective understanding, any agreement between speaker and hearer may be purely verbal. Both may agree that "we ought always to obey the law" and yet have vastly different, even contradictory, ideas about what this means. It is one thing to understand these words in the sense that one could give a roughly synonymous equivalent or perhaps even translate them into a foreign language: It is quite another thing to understand what it means to be bound to the law.

This conception entails that communication bearing on normativity must be indirect because the "second reflection" that explains the emergence of actual binding force requires a kind of active involvement and appropriation by the person receiving the communication, and this means that direct communication is of no value. This might also be true for cases of communication about what Kierkegaard would call objective matters; someone who wants to explain some difficult point about mathematical equations cannot simply transfer his or her knowledge to me without effort on my part. However, there does seem to be a sense in which communication about subjective matters requires a deeper kind of involvement on the part of the recipient of the communication; and this is the sense that matters to legal efficacy. For this very reason, even though indirect communication is the basic form of persuasiveness, it is probably an overstatement to claim that it actually consumes the entirety of persuasiveness. It is true that, if one is to understand and internalise some set of norms, such a thing is possible only when they are persuasive, i.e., based on persuasive reasons for action in the Razian sense. However, the possibility that there is a kind of communication that does not involve a deep level of commitment on the addressee's part concerning how the contents communicated affect her (what Kierkegaard called direct communication) might entail the existence of persuasiveness which is not necessarily indirect communication.

Still, in the context of a normative concept of legal efficacy, there does not seem to be a pressing need to distinguish between persuasiveness and indirect communication given that they express the same success forms of communication albeit within different frames of reference. For instance, it might be possible (and perhaps even helpful) to say what Kierkegaard is saying in relation to subjective and objective communication by using the Razian distinction between committed and detached statements, according to which committed statements express a personal acceptance of contents, whereas detached statements express some external point of view from which contents are accepted as legitimate (Raz 1979, 153-7; 1999, 171-7). What justifies using the Kierkegaardian perspective on normative efficacy in addition to the notion of persuasiveness is that its emphasis on communication (involving a relation between speaker and addressee) rather than merely on reasons and statements (involving a relation between the addressee 
and her own reasons for acting or nonacting, and between the addressee and her own uttered statements) is better suited to making sense of how one can identify a legal system's addressees and ascertain its efficacy by their actions.

Indirect communication is here akin to Hart's internal point of view. But it does not simply emphasise the importance of the recipient of norms to explain normativity: It also helps to explain how a norm with a pretence to legality becomes a norm with binding force. A norm is successful in creating an obligation not only if its addressee receives the information contained in it, but mostly if the addressee has the capability to consider himself bound by the norm. This capability is a form of inwardness. Ultimately, one person or institution cannot give obligatoriness to another. The direct testimony one person (for instance, an official or a fellow citizen) offers to another with regard to the norm's bindingness can only be the occasion for this to happen. If one takes "communication" to denote successful communication, a legal official can communicate only indirectly, even when he/ she bears direct testimony to his/her bindingness.

As a result, the addressees of a legal system are not necessarily those identified in the norms or those which the drafters of norms intended to address. Rather, the addressees of a legal system are those who are presupposed in nonefficacious standards determining the characteristics that provide access to the norm's binding force; and these nonefficacious standards only become binding the moment they are received and understood by those who recognise themselves as addressees of such standards. Consequently, all those who have the status of being an "addressee" of norms in this sense of indirect communication meet the basic condition for being agents of legal efficacy, whether they are officials or members of society at large.

\section{Efficacy as Constitutive Obedience}

The idea that efficacy can be the mere coincidence between facts and certain normative contents seems to presuppose the possibility that brute facts can fit into normative predictions. Trust in the capacity of the external point of view to determine efficacy mirrors this idea: that acts of compliance and/or application of sanctions to noncompliance are empirically independent from the norms but can be normatively imputed to them. However, efficacy as persuasiveness and indirect communication entail that there is not just a coincidence between facts and normative contents but also an emergence of facts whose very existence depends on their normative framework. Emphasis on the capacity of the internal point of view to determine efficacy has this merit: It helps to explain how the legal facts that matter for efficacy are not autonomous occurrences predicted by norms but rather phenomena whose conditions of existence are already normative (Greenberg 2004). When someone pays taxes in compliance with tax laws, the acts of payment are neither predicted by tax laws nor mere proof of their efficacy; rather, there are no taxes to pay without the prior binding force of tax laws, which means that efficacy is the creation of a new fact (empirically nonexistent per se without law) called "tax."

Acknowledging this fact implies that efficacy cannot be measured equally for all types of norms. Those norms that create the facts of compliance are efficacious in a different sense than the one attributed to those norms that merely stipulate certain 
facts of compliance. The main distinction within this frame of reference is between constitutive and regulatory norms. ${ }^{5}$

Constitutive norms are those that define institutional activities. Regulative norms pertain to activities that are logically independent of the norms, whereas activities that fall under constitutive norms depend logically on them. If someone hands over a piece of paper to someone else with the letters B-I-L-L printed on it, this activity can be legally regulated (for instance, the paper must not be poisonous, the person handing it over must not be under coercion, and so on), but in order for someone to hand over a bill to someone in such a way as that the obligation to pay is binding, this activity must be legally constituted. A regulative norm can be expressed by the simple formula " $X$ ought to do $Y^{\text {"; }}$, those theories that rely on the external aspect of efficacy simply impute the observance of $Y$ to $X$. But constitutive norms are expressed by a different locution, such as " $X$ counts as $Y$ in context $C$," where acts of type $X$ are possible independently of the norm that regulates them and acts of type $Y$ cannot be performed in the absence of a constitutive norm that defines such acts. The relation between acts of legal practice and the normative content of law is for the most part determined by more or less explicit constitutive rules stating that an act of type X "counts as" the realisation of a given legal institution with a specific normative import (MacCormick 1986). Consequently, constitutive norms do not indicate the presence of obligations per se but are efficacious to the extent that acts of type $Y$ are indeed "by and large accepted" as facts in a given community.

Constitutive norms define and create (the possibility of) institutional forms of behaviour. As a result, the underlying conception of institutions is that they are (systems of) constitutive norms. A legal system is a system based on constitutive norms (Searle 1969, 33), in which the "counts as" relation between X and Y is mostly a rational normative determination (based on reasons) and the context $C$ is a factual setting that includes boundaries to institutional constitution (Roversi 2010).

The upshot of the argument of indirect communication applied to constitutive norms is that it shifts the power to create norms from those who issue them to those who obey them. This represents also a shift of paradigm in the analysis of efficacy. The prevailing paradigm in the light of which efficacy is often understood is that of efficient ${ }^{6}$ transitive causality: A norm is considered efficacious if it somehow induces its addressees to behave in accordance with its contents; literally,

\footnotetext{
${ }^{5}$ The main idea behind the conventional nature of constitutive norms can be traced back to Anscombe (1958), as well as to Wittgenstein (1953, pars. 197, 205, 567). Proposals for understanding particular institutional phenomena or institutions generally in terms of constitutive rules have been made by, among others, Rawls (1955), Midgley (1959) and Searle $(1969,1995)$. Searle's account of constitutive rules is perhaps the most developed one, and it remains the main point of reference in the contemporary literature on the subject.

${ }^{6}$ Efficient causality is different from teleological causality. Those upholding a formal morality inherent in the principles of legality (Fuller 1969, 200-24) endeavoured to define conditions for the efficacy of a system of rules, where efficacy meant the ability of the system to serve the ultimate ends for which the rules are deployed rather than the actual motivation of behaviour. Law is here the product of the interplay of purposive orientations: This is a strictly teleological paradigm. The gap between the causal and the teleological perspectives explains why Fuller's critics often claim that he confused morality with efficacy, whereas his replies tend to emphasise the idea that purposeless efficacy is something strange to the law.
} 
efficacy implies considering acceptance, compliance, and sanctions to offences as something resembling the effects of norms. ${ }^{7}$ This paradigm is fit for regulatory norms, but completely inadequate for constitutive norms.

The new paradigm of efficacy is that of efficient immanent causality, according to which the cause (binding force) can only be considered a cause (actual bindingness) with the actual production of the effect (being subject to a binding force). In this sense, normativity cannot be established from the viewpoint of government, rulers or institutions (those who issue norms) but rather from the viewpoint of those who obey. There are no efficacious norms except those which actually constitute in their addressees an awareness of their binding force. The authority of lawgivers is simply nonexistent unless it can rely on actual indirect communication. This entails that the existence of (an awareness of) obedience is the source of the authority of law, not the other way round. This dimension of efficacy can be called constitutive obedience.

In what sense can the awareness of obedience constitute an efficacious legal system? The obvious answer is that a system is efficacious when its subjects acknowledge its binding force and act accordingly, that is, when the norms comprising it include claims to authority that are actually put in practice and without which there would be no legal system in the first place. In other words, a legal system is efficacious when its inherent constitutive norms actually create facts in a given community. In order for a legal system to be efficacious, the norms that have to be in force are all those without which other norms that depend on them in order to be legally binding cannot be considered in force. The distinction is not so much between secondary and primary norms, as put forth by Hart, but rather between constitutive norms and nonconstitutive norms in a system. The persuasive dimension of the former to the members of a given community founds an efficacious legal system.

In this sense, the claim that law's authority does not come from an external source but is internal to the practice of obeying legal norms seems to be a simple consequence of conceptualizing efficacy in terms of persuasiveness. In other words, efficacy as constitutive obedience is nothing more than persuasiveness specifically applied to a legal system that distinguishes between constitutive and nonconstitutive norms, in which the emphasis is placed on the former.

\section{The Efficacy of Individual Norms}

Most legal theories assert that individual norms do not need to be efficacious in order to be binding (exceptions are Ross 1968 and Kelsen 1979, 114). They simply accept that integration within an efficacious legal system is sufficient fulfilment of the condition of efficacy for an individual norm's bindingness. Accordingly, the claim that a legal system must be by and large efficacious in order for the norms

\footnotetext{
${ }^{7}$ The paradigm of efficient causality does not entail the acknowledgement that norms can cause actual behaviour. If it did, there would be a category mistake between the deontic and the ontic realms. Rather, the paradigm of efficient causality should be understood in the sense that norms function as if they were causes of those behaviours whose underlying motivations and reasons for existing in the first place are explained in the light of those norms. Kelsen (1943; 1967, 76-101), for instance, identified this causal-like connection with the concept of imputation.
} 
composing it to be in force entails that all the norms of a legal system are efficacious in the sense that they are norms of an efficacious legal system, even though they may not be efficacious in the sense that they are generally adhered to and accepted or internalized as binding. Membership of an efficacious legal system seems to be a sufficient condition of efficacy in the first sense. However, this does not necessarily mean that the question of whether an individual norm is adhered to or internalised as binding is irrelevant in the determination of efficacy. Rather, it means that individual norms seem to be subject to different kinds of tests with regard to their efficacy: the test of efficacy as individual norms belonging to a legal system and the test of efficacy as individual norms per se. The first test allows for the classification of an individual norm as efficacious or nonefficacious; the second test allows for the qualification of an efficacious norm as more or less efficacious.

The combination of the two tests creates a multilayered measure of efficacy. The first test requires the conditions of persuasiveness, indirect communication, and constitutive obedience to be met with regard to legal systems, as well as the condition of membership with regard to the individual norm. This test is paramount to the identification of existent legal systems and norms. The second test requires the conditions of persuasiveness, indirect communication, and constitutive obedience to be met with regard to each individual norm. This test presupposes the existence of positive law, but it can be an important element of bindingness that must be taken into account in complicated cases of conflicts of norms and/or sources, as well as in cases of probable derogation through customary law (desuetudo). This test can thus function as a qualifying criterion that helps to determine the actual law in force in hard cases.

These different layers of an individual norm's efficacy derive from two different characteristics of legal systems: the fact that they are hierarchical settings of norms in which certain compulsory norms are binding if power-conferring norms validate them, and the fact that they comprise norms whose addressees are sometimes society at large and other norms whose addressees are sometimes only certain sectors of the population.

With regard to the first characteristic, compulsory norms can hardly be efficacious if the power-conferring norms that allow for the very possibility of their existence are not already efficacious. However, the contrary must somehow also be true, for power-conferring norms are only efficacious when they are able to produce actually efficacious compulsory norms. In fact, even though all norms, including power-conferring norms, can be applied (observed or not, complied with or not), only commands and prohibitions can be followed or not, executed or not. Only by means of compulsory norms (such as commands and prohibitions) arising out of the exercise of normative powers can these normative powers be identified as efficacious. It is only by analysing whether the norms emerging from powerconferring norms are actually efficacious that it becomes possible to decide whether the power mentioned in the power-conferring norms was efficaciously conferred. The general acceptance and compliance with compulsory norms therefore seems determinant not only of their efficacy as such but also of the efficacy of the power-conferring norms from which they derive. However, this connection is very general, since a power-conferring norm can confer powers to create several compulsory norms. In order for a power-conferring norm to be efficacious, it is 
necessary for at least one (and not necessarily all) of the compulsory norms also to be efficacious.

With regard to the second characteristic, the problem of scope arises. Suppose that an individual compulsory norm in a legal system derives its binding force from a power-conferring norm that does not seem to be generally adhered to and accepted or internalised. Still, the individual norm in question is generally adhered to and accepted or internalised by society at large. For instance, an ordinary citizen places a stop sign at an intersection and everybody recognises it as binding law. Is it reasonable to state definitively that it is by and large inefficacious? Or suppose the opposite case. For instance, city officials in charge of enacting traffic laws that are generally accepted as compulsory place a stop sign at an intersection that is openly disregarded by society at large. Is it reasonable to state definitively that it is by and large efficacious, despite the fact that there is no indirect communication involved?

These requirements of efficacy establish a spectrum of different levels of efficacy of an individual norm that can be presented in the following way.

(i) A compulsory norm that is efficacious to society at large and to (the legal system's) officials.

(ii) A compulsory norm that is efficacious to society at large but not to officials, although the power-conferring norms to which the compulsory norm is related is efficacious to officials.

(iii) A compulsory norm that is efficacious to society at large but not to officials, considering also that the power-conferring norm to which the compulsory norm is related is not efficacious to officials.

(iv) A compulsory norm that is not efficacious to society at large, but it is considered efficacious by officials.

(v) A compulsory norm that is not efficacious to society at large and to officials, although the power-conferring norm to which the compulsory norm is related is efficacious to officials (in the sense that other compulsory norms deriving therefrom are efficacious to officials).

(vi) A compulsory norm that is not efficacious to society at large and to officials, considering also that the power-conferring norm to which the compulsory norm is related is not efficacious to officials, although it depends on another higher power-conferring norm that is efficacious to officials.

It is difficult to place this spectrum of different kinds of efficacy in a hierarchical order, even though it is reasonable to suppose that (i) stands for legal efficacy whereas (vi) is a borderline case of efficacy/inefficacy. With regard to the relations between norms, the efficacy of power-conferring norms might be more important than the efficacy of compulsory norms, but since their effectiveness depends upon compulsory norms, it is difficult to establish which norms' efficacy has precedence over the others'. With regard to the dimension of scope, a norm whose addressees are a country's entire population can be as efficacious as a norm whose addressees are two individuals insofar as the entirety of addressees accept and adhere to the norm.

However, two arguments can be inferred from this overview of layers of efficacy. The first is that efficacy can function as a valuable test to ascertain which law is 
binding in a particular case whenever two apparently valid norms conflict with each other. If two different norms in a case seem to pass the test established by the set of criteria that classifies positive law, and there are no apparent norms applicable in the resolution of the conflict, efficacy can be a qualifying criterion establishing which of these norms is binding in that case. A legal system is either efficacious or not, but an individual norm in the legal system can be more or less efficacious; the most efficacious norm (the one that is actually persuasive to its addressees and which depends upon power-conferring norms that are actually persuasive to their addressees) can thus provide a reason to overrule the least efficacious norm when they come into conflict inside an efficacious legal system.

The second argument is that even though quantity is not an essential element of efficacy, the identification of the most efficacious norm in a particular case cannot simply disregard the fact that the efficacy of individual norms in legal systems associated with democratic regimes must have some relation with quantity. The reason underlying this minimum connection is that norms with a higher level of generality-such as those inherent in the rule of law, as opposed to the decrees issued in bureaucratic regimes-appeal to an acceptance by a larger number of people, which somehow protects them from being disputed in areas that are outside the legal system's institutional framework but to which the legal system is not indifferent (such as politics, economics, morality, religion, and civil society). In this sense, the search for the most efficacious norm in a given case cannot neglect the importance of the norm's persuasive character vis-a-vis the community that supports the entire legal system in which the norm (and the decisions following therefrom) is binding.

\section{Concluding Remarks}

The purpose of the argument presented here was twofold. The first was to establish that efficacy as dominance is justified normativity in a factual context, which in turn would constitute a theoretical yardstick determining a threshold of overwhelming acceptance of a law's bindingness. In other words, the intention was to establish what it means to say that a legal system is in force in a given community, which could help determine the actual law in force in difficult cases, including those involving conflicts of norms and of sources.

As a result, it should be explicit how such a notion of efficacy differs from theories of legal validity that emphasise the success of communication between participants in a given system of law. In fact, the claim that a legal system is efficacious if it is based on persuasive reasons, it is communicated in the proper way (in the sense of direct communication), and its authority stems from within the legal practice, is immune to axiologically charged contents or procedures containing an inherent "claim to correctness" (Alexy 2010). According to this normative concept of legal efficacy, binding force implies not only that one ought to do what the legal system prescribes, but also that the system is sufficiently accepted as justified by those who fulfil the role of its addressees, regardless of the specific contents and of the procedural principles (Habermas 1996, 118-31) by which the success of such a justification occurs. In a sense, the proposed reconceptualisation of efficacy may easily integrate a general theory of legal validity, even though it falls short of even aspiring to become a fully developed theory of validity. 
The second purpose was to show that efficacy is not only important to the distinction between positive law in force and positive law not in force, but it is also paramount to the success of legal systems supported by democratic regimes. The nature of indirect communication and of constitutive obedience raises the question of the genuine source of legal normativity. In fact, what comes first: Commands or obedience? Power or efficacy? The traditional conceptual framework of efficacy is defined in terms of giving and executing commands, an idea that presupposes lawgiving institutions or people imposing certain contents. However, the conception of efficacy put forward here does not rely on the command-obedience relationship, but rather on the internal aspect of obedience as the source of normativity. This can be an important field of research in democratic theory insofar as it traces the authority of all legal systems to those subject to them.

It might be too ambitious to claim that the characteristics of efficacy outlined above-persuasiveness, indirect communication and constitutive obedience with regard to legal systems, and membership with regard to individual norms - form a general theory of legal efficacy. However, they contradict the idea that legal theory does not have much to say about efficacy, although it is the most decisive criterion in the determination of existing legal systems.

Universidade Nova de Lisboa
Nova Institute of Philosophy
Av.de Berna, 26 - 4th Floor
1069-061 Lisbon
Portugal
E-mail: andredoscampossantos@gmail.com

\section{References}

Abizadeh, A. 2008. Democratic Theory and Border Coercion: No Right to Unilaterally Control Your Own Borders. Political Theory 36(1): 37-65.

Alexy, R. 2010. The Argument from Injustice: A Reply to Legal Positivism. Trans. B. Litschewski Paulson and S. L. Paulson. Oxford: Oxford University Press.

Anscombe, G. E. M. 1958. On Brute Facts. Analysis 18(3): 69-72.

Bulygin, E. 1990. An Antinomy in Kelsen's Pure Theory of Law. Ratio Juris 3(1): $29-45$.

Dworkin, R. 1978. Taking Rights Seriously. 2nd. ed. Cambridge, MA: Harvard University Press.

Evans, C. S. 2009. Kierkegaard: An Introduction. Cambridge: Cambridge University Press.

Fuller, L. 1969. The Morality of Law, revised ed. New Haven, CT: Yale University Press.

Goodin, R. E. 2007. Enfranchising All Affected Interests, and Its Alternatives. Philosophy and Public Affairs 35(1): 40-68.

Greenberg, M. 2004. How Facts Make Law. Legal Theory 10: 157-98.

Habermas, J. 1996. Between Facts and Norms. Trans. W. Rehg. Cambridge: Polity.

Hart, H. L. A. 1994. The Concept of Law. 2nd ed. Oxford: Clarendon.

Hoerster, N. 1987. Die rechtsphilosophische Lehre vom Rechtsbegriff. Juristische Schulung 27: 181-88. 
Kelsen, H. 1943. Society and Nature: A Sociological Inquiry. Chicago, IL: The University of Chicago Press.

Kelsen, H. 1949. General Theory of Law and State. Trans. A. Wedberg. Cambridge, MA: Harvard University Press.

Kelsen, H. 1967. Pure Theory of Law. Trans. M. Knight. Berkeley, CA: University of California Press.

Kelsen, H. 1979. Allgemeine Theorie der Normen. Vienna: Manz.

Kierkegaard, S. 2009. Concluding Unscientific Postscript. Ed. and trans. A. Hannay. Cambridge: Cambridge University Press.

Lamond, G. 2001. Coercion and the Nature of Law. Legal Theory 7(1): 35-57.

Lopez-Guerra, C. 2005. Should Expatriates Vote? The Journal of Political Philosophy 13(2): 216-34.

Lyons, D. 1984. Ethics and the Rules of Law. Cambridge: Cambridge University Press.

MacCormick, N. 1986. Law as Institutional Fact. In An Institutional Theory of Law: New Approaches to Legal Positivism. Ed. N. MacCormick and O. Weinberger, 4976. Dordrecht: Kluwer.

Midgley, G. C. 1959. Linguistic Rules. Proceedings of the Aristotelian Society 59: 271-90.

Nino, C. S. 1978. Some Confusions Surrounding Kelsen's Concept of Validity. Archiv fer Rechts- und Sozialphilosophie 64: 357-77.

Rawls, J. 1955. Two Concepts of Rules. Philosophical Review 64(1): 3-32.

Raz, J. 1970. The Concept of a Legal System: An Introduction to the Theory of Legal System. 2nd ed. Oxford: Clarendon.

Raz, J. 1979. The Authority of Law. New York: Oxford University Press.

Raz, J. 1985. Authority, Law and Morality. The Monist 68(3): 295-24.

Raz, J. 1999. Practical Reason and Norms. 2nd ed. Oxford: Oxford University Press.

Ross, A. 1968. Directives and Norms. London: Routledge \& Kegan Paul.

Ross, A. 1998. Validity and the Conflict between Legal Positivism and Natural Law. In Normativity and Norms. Critical Perspectives on Kelsenian Themes. Ed. S. L. Paulson and B. Litschewski Paulson, 147-63. Oxford: Clarendon.

Ross, H. 2001. Law as a Social Institution. Oxford: Hart.

Roversi, C. 2010. Constitutive Rules in Context. Archiv fur Rechts- und Sozialphilosophie 96: 223-38.

Searle, J. 1969. Speech Acts. Cambridge: Cambridge University Press.

Searle, J. 1995. The Construction of Social Reality. New York: The Free Press.

Shapiro, I. 1999. Democratic Justice. New Haven, CT: Yale University Press.

Wittgenstein, L. 1953. Philosophical Investigations. Trans. G. E. M. Anscombe. Oxford: Blackwell. 